\author{
Marquette University \\ e-Publications@Marquette
}

2003

\title{
An XPS investigation of thermal degradation and charring on poly(vinyl chloride)-clay nanocomposites
}

Jianxin Du

Beijing Institute of Technology

Dongyan Wang

Marquette University

Charles A. Wilkie

Marquette University, charles.wilkie@marquette.edu

Jiangqi Wang

Beijing Institute of Technology

Follow this and additional works at: https://epublications.marquette.edu/chem_fac

Part of the Chemistry Commons

\section{Recommended Citation}

Du, Jianxin; Wang, Dongyan; Wilkie, Charles A.; and Wang, Jiangqi, "An XPS investigation of thermal degradation and charring on poly(vinyl chloride)-clay nanocomposites" (2003). Chemistry Faculty Research and Publications. 137.

https://epublications.marquette.edu/chem_fac/137 


\section{Marquette University}

\section{e-Publications@Marquette}

\section{Chemistry Faculty Research and Publications/College of Arts and Sciences}

This paper is NOT THE PUBLISHED VERSION; but the author's final, peer-reviewed manuscript. The

published version may be accessed by following the link in th citation below.

Polymer Degradation and Stability, Vol. 79, No. 2 (2003): 319324. DOI. This article is (C) Elsevier and permission has been granted for this version to appear in e-Publications@Marquette. Elsevier does not grant permission for this article to be further copied/distributed or hosted elsewhere without the express permission from Elsevier.

\section{An XPS Investigation of Thermal Degradation and Charring on Poly(vinyl chloride)-clay Nanocomposites}

Jianxin Du

School of Chemical Engineering \& Materials Science, Beijing Institute of Technology, 100081 Beijing, China

Dongyan Wang

Department of Chemistry, Marquette University, Milwaukee, WI

Charles A. Wilkie

Department of Chemistry, Marquette University, Milwaukee, WI

Jianqi Wang

School of Chemical Engineering \& Materials Science, Beijing Institute of Technology, 100081 Beijing, China

\section{Abstract}

More information concerning the thermal degradation and charring of nanocomposites of poly(vinyl chloride), dioctyl phthalate and clay has been obtained by the use of X-ray photoelectron spectroscopy and the acquisition of the carbon (C1s), chlorine ( $\mathrm{Cl} 2 \mathrm{p}$ ), and oxygen (01s) spectra. In the cases of polystyrene-clay and poly(methyl methacrylate)-clay nanocomposites, it has been shown that the clay migrates to the surface as the temperature is raised and the polymer degrades, thereby confirming the barrier properties as a mechanism by which these 
materials function. For PVC-clay nanocomposites the surface at high temperatures is dominated by carbon, and not the oxygen of the clay. The presence of the clay does retard the chain-stripping degradation of the PVC and the enhanced char formation accounts for the observation of enrichment of carbon.

\section{Keywords}

Poly(vinyl chloride) (PVC), Nanocomposites, X-ray photoelectron spectroscopy (XPS), Thermal degradation, Charring

\section{Introduction}

Polymer clay nanocomposites have attracted intense interest from academic and industrial researchers in the past decade [1], [2], [3], [4], [5], [6], [7], [8], [9], [10]. While many polymer-clay nanocomposites have been reported, including polyamide-6 (PA6), polystyrene (PS), poly(methyl methacrylate) (PMMA) and polypropylene (PP), little attention has been given to poly(vinyl chloride) (PVC). Ishida ${ }^{[11]}$ reported a novel approach to nanocomposite preparation in which PVC was blended with a tin stabilizer in the presence of clay and epoxy with a spatula or a mortar and pestle; only X-ray diffraction (XRD) results have been reported. In a series of papers, we have reported on the preparation and characterization of PVC-clay nanocomposites formed by both melt and solution blending [12], [13], [14]. The effects of the clay loading level, the presence and amount of plasticiser, melt blending time and annealing time, etc., on the structure of the nanocomposite and the thermal and mechanical properties have also been investigated.

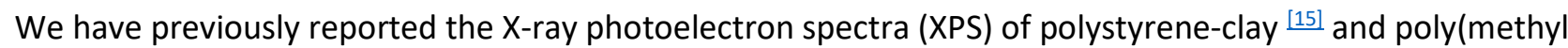
methacrylate)-clay $\stackrel{[16]}{ }$ nanocomposites. From this work one can show that as the polymer undergoes degradation the clay becomes the surface layer, thereby confirming the barrier mechanism that has been proposed by Gilman to account for the enhanced thermal stability of polymer-clay nanocomposites $\frac{[17]}{\text {. The }}$

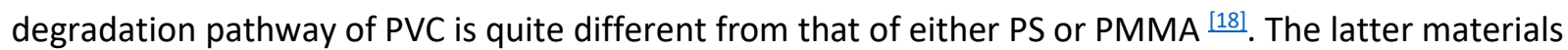
completely volatilize upon degradation while PVC forms char. Thus one may not necessarily expect to observe the same behaviour for PVC nanocomposites as seen for PS and PMMA materials.

In this paper we report on the XPS of PVC nanocomposites, both with and without plasticizer. The accumulation or loss of carbon, chlorine and oxygen, as well as silicon and aluminium, from the surface is followed.

\section{Experimental}

\subsection{Materials}

The organically modified clay, MTEt2 (M: methyl; T: tallow with 65\%C18, 30\%C16 and 5\%C14; Et: 2-hydroxy ethyl), was a gift from Southern Clay Products, Inc. Two samples of PVC were acquired from Aldrich Chemical Company; one has an inherent viscosity of $0.68\left(V_{\text {inh }} 0.68\right)$ and $\mathrm{Mn}=35,000, \mathrm{Mw}=62,000$; the other has an inherent viscosity of $1.40\left(V_{\text {inh }} 1.40\right)$, with $M n=99,000$ and $M w=233,000$. Dioctyl phthalate (DOP) was provided by Eastman Chemical Company. Zinc stearate, $\left[\mathrm{Zn}\left(\mathrm{O}_{2} \mathrm{C}_{18} \mathrm{H}_{35}\right)_{2}, 98 \%\right]$, was obtained from Research Chemicals, Ltd., and calcium stearate, $\left[\mathrm{Ca}\left(\mathrm{O}_{2} \mathrm{C}_{18} \mathrm{H}_{35}\right)_{2}\right]$, from Johnson Matthey Company. All materials were used as received.

\subsection{Preparation of nanocomposites}

Melt blending was performed using a Brabender Plasti-Corder at $180^{\circ} \mathrm{C}$, usually for $5 \mathrm{~min}$ at high rotor speed (60 $\mathrm{rpm})$, followed by compression moulding at $170-180^{\circ} \mathrm{C}$ for about $30 \mathrm{~s}$ to give $1 \mathrm{~mm}$ thick plaques. The plaques were annealed in a vacuum oven for $24 \mathrm{~h}$, either at 90 or at $104{ }^{\circ} \mathrm{C}$, as previously described [12], [13]. These samples were characterized by XRD, TEM, thermogravimetric analysis (TGA), cone calorimetry and mechanical properties. The materials, which are produced by melt blending are best described as a mixture of immiscible and intercalated structures. 


\subsection{Instrumentation and sample preparation}

The XPS experiments were carried out as previously described $[15,[166,[19],[20]$, using the pseudo in situ technique in which the sample is heated outside of the XPS chamber under an argon atmosphere. During the analysis the sample orientation must be kept unchanged from beginning to end. The spectra were obtained using a PerkinElmer PHI 5300 ESCA system at $250 \mathrm{~W}(12.5 \mathrm{kV}$ at $20 \mathrm{~mA})$ under a vacuum better than $10^{-6}$ Pascal (10-8 Torr). The spectrometer was calibrated using the binding energy of adventitious carbon as $284.6 \mathrm{eV}$. The samples were prepared by solvent casting a thin film from tetrahydrofuran (THF) solution onto aluminium foil. The d-spacing of the nanocomposites before and after dissolution was determined and no change in $\mathrm{d}$-spacing was found.

\section{Results and discussion}

\subsection{Thermal degradation and charring}

As previously reported $[12],[13],[14]$, the thermal and mechanical properties of PVC-clay nanocomposites are determined by the amount of clay and DOP present in the formulations. The identification used throughout this work is to denote the sample as PVC-0-0; the first number is the wt.\% of clay while the second number is the wt.\% of DOP. Thus a sample identified as PVC-5-30 is a nanocomposite, which contains 5 wt. $\%$ clay and 30 wt.\% DOP. The thermal stability of the PVC-clay nanocomposites and virgin PVC can be assessed from the $\mathrm{Cl} 2 \mathrm{p}$ spectra as function of temperature (Fig. 1). Chlorine is lost from virgin PVC, PVC-0-0, as early as $100{ }^{\circ} \mathrm{C}$, a value which is significantly lower than that seen in a TGA experiment; this is attributable to the higher sensitivity of XPS relative to TGA $\stackrel{[21]}{2}$. Approximately $50 \%$ of the chlorine remains at $230{ }^{\circ} \mathrm{C}$ and $8 \%$ remains at $460{ }^{\circ} \mathrm{C}$. Nanocomposites that contain $2 \%$ and $30 \%$ clay, PVC-2-0 and PVC-30-0, show much improved thermal stability.

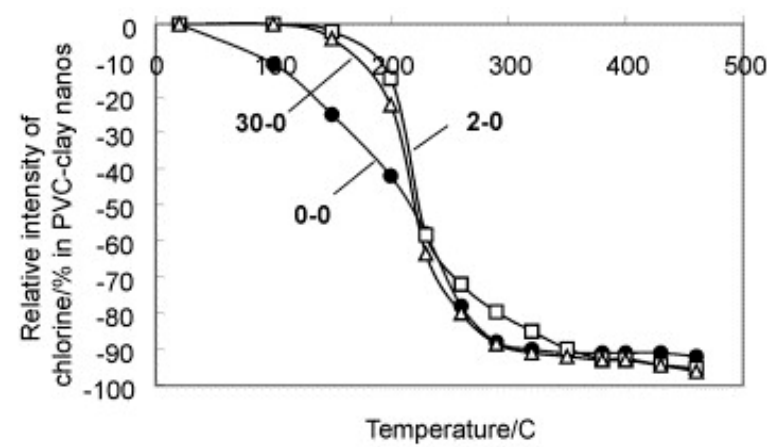

Fig. 1. Relative intensity of chlorine in PVC-clay nanocomposites as a function of temperature.

The effect of DOP on chlorine loss as a function of temperature, as evaluated from the $\mathrm{Cl} 2 \mathrm{p}$ spectra, is shown in Fig. 2. This figure includes both PVC with and without DOP. The presence of DOP has an enormous effect on the chlorine intensity. If one compares PVC with that containing $35 \%$ DOP, one sees a more rapid loss of chlorine below $120^{\circ} \mathrm{C}$, followed by an accumulation between 120 and $250{ }^{\circ} \mathrm{C}$ and then a loss of chlorine. In the case of the sample that contains $2 \%$ clay, there is an initial decrease and then the curve follows very well that of PVC-20 .

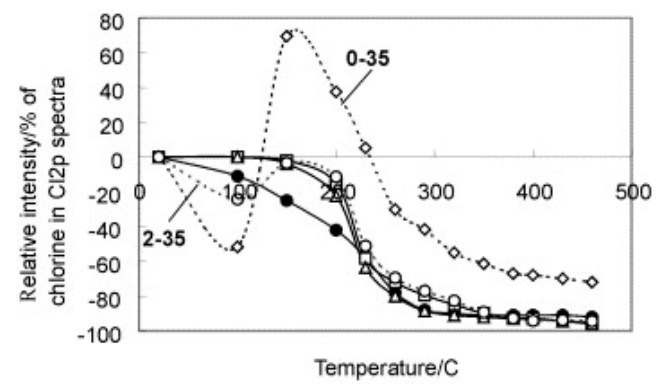

Fig. 2. Relative intensity of chlorine in PVC-clay-DOP nanocomposites as a function of temperature. 
This difference is surely due to interaction between PVC and DOP. The compatibility between DOP and PVC is comparable with that between DOP molecules and between PVC molecules. When DOP is mixed with PVC, the van der Waals forces between polymer chains will be partially disrupted by the DOP, which must render the polymer swollen. In other words, the density of the polymeric matrix tends to decrease, which leads to a reduction in the number of chlorine atoms per unit area, as observed between ambient and $120^{\circ} \mathrm{C}$. As the temperature increases, the gradual migration of DOP from the bulk towards the surface results in an increased density and an increase in the amount of chlorine. For the PVC-2-35 system, clay particles may act as physical cross-linking sites and stabilize the dimensional changes (the polymer is less swollen) and lower the rate at which DOP can migrate to the surface, leading to a decreased surface enrichment of chlorine.

The carbon spectra provides complementary information; these results are shown in Fig. 3 , Fig. 4. The accumulation of carbon is initially a little lower in the presence of clay than in its absence, but, above $300{ }^{\circ} \mathrm{C}$ the presence of clay in both PVC-2-0 and PVC-30-0 gives greater carbon intensity. This increase in carbon intensity is usually attributed to some type of cross-linking; this is probably not a classical cross-linking process but is more likely simply some, perhaps transient, carbon accumulation and may be attributed to a physical cross-linking, i.e. entanglements. One may calculate from the C1s spectrum that in PVC-30-0 the extent of cross-linking at $460{ }^{\circ} \mathrm{C}$ is $52 \%$ while it is $32 \%$ for PVC-2-0 and $24 \%$ for PVC-0-0. The curve for PVC-30-0 crosses that of PVC-0 -0 at $250{ }^{\circ} \mathrm{C}$ while that of PVC-2-0 crosses at $350^{\circ} \mathrm{C}$, i.e. the greater is the amount of clay, the earlier is the cross-linking manifested.

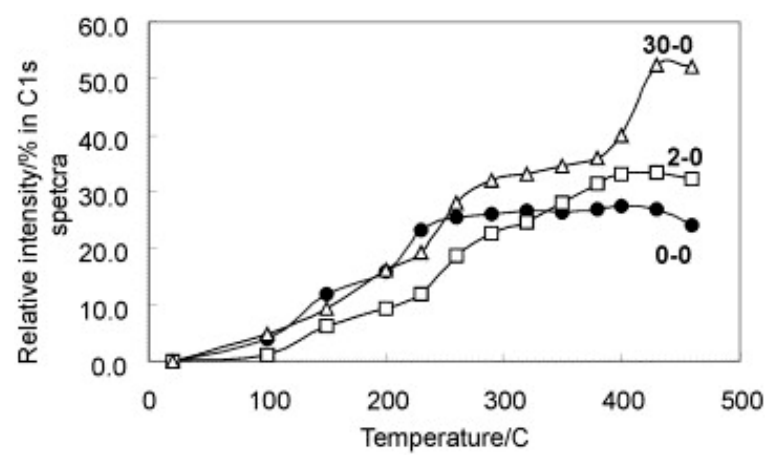

Fig. 3. Relative intensity of carbon in PVC-clay nanocomposites as a function of temperature.

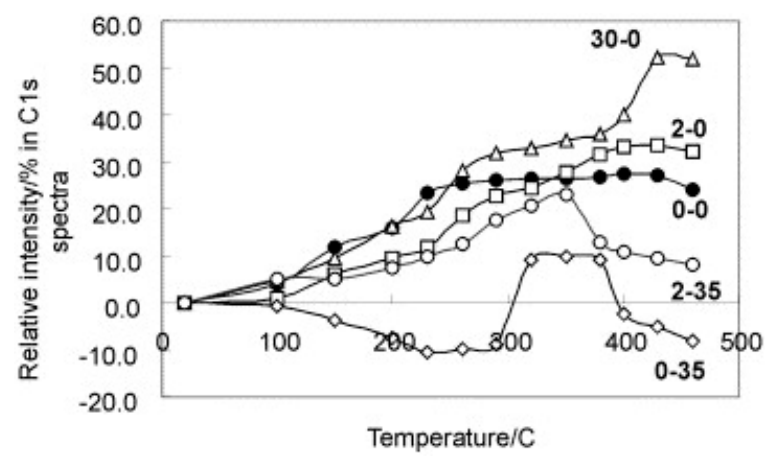

Fig. 4. Relative intensity of carbon in PVC-clay-DOP nanocomposites as a function of temperature.

The effect of DOP can be observed from Fig. 4. In the presence of DOP there is less accumulation of carbon, i.e. less cross-linking. This is quite complementary to the observations based upon the $\mathrm{Cl} 2 \mathrm{p}$ spectrum. In the absence of clay, swelling of the polymer occurs, which leads to a smaller amount of carbon at the surface for virgin PVC. When clay is present, some of this swelling is prevented and the accumulation of carbon is quite similar to material, which does contain DOP up to about $350^{\circ} \mathrm{C}$. At higher temperatures, carbon is lost from the surface. This is quite possibly attributable to the loss of DOP, which must rise to the surface as the temperature increases. 
The variation of the amount of oxygen at the surface for PVC and its nanocomposites is shown in Fig. 5 , Fig. 6. For virgin PVC one sees that there is a steady increase in the amount of surface oxygen. This must be attributable to the presence of adventitious oxygen, arising from the pseudo in situ sample preparation during heating and this has been previously observed for other polymeric systems [15], [16]. For PVC-2-0 the amount of oxygen at the surface is the same as that in virgin PVC up to about $380^{\circ} \mathrm{C}$, above that oxygen decreases for the nanocomposite but increases for virgin PVC. In the system which contains the most oxygen, PVC-30-0, there is a large increase in oxygen concentration beginning at $200^{\circ} \mathrm{C}$ and this then falls off at about $350^{\circ} \mathrm{C}$. In a material, which contains so much clay, there must be an accumulation of oxygen at the surface. The surprising thing is its decline at higher temperatures. This precipitous decline occurs at about the same temperature at which carbon begins to accumulate in the C1s spectrum. The conclusion is that, since PVC is a char-former, the char eventually covers the surface to the exclusion of oxygen.

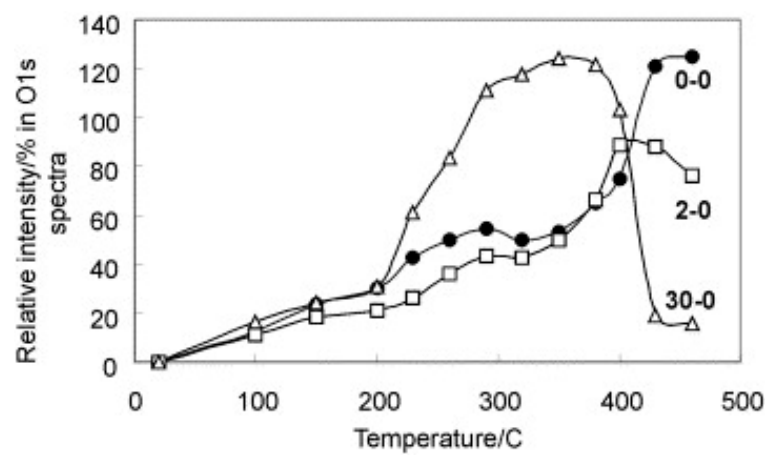

Fig. 5. Relative intensity of oxygen in PVC-clay nanocomposites as a function of temperature.

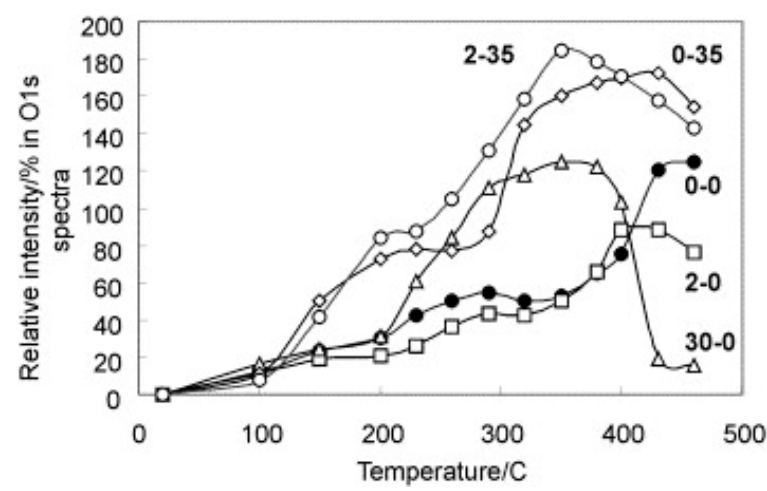

Fig. 6. Relative intensity of oxygen in PVC-clay-DOP nanocomposites as a function of temperature.

Two mechanisms have been proposed by which nanocomposites offer enhanced thermal stability to polymers; barrier properties ${ }^{[17]}$ and radical trapping ${ }^{[10]}$. In previous work using XPS on PS and PMMA nanocomposites, we have shown that oxygen accumulates at the surface of the nanocomposite much more than it does in the virgin polymers or from a system in which a clay is simply present as a filler 115$],[16]$. This apparently confirms that the clay does act as a barrier and will serve to prevent, for a time, the escape of volatiles from a polymer and to insulate the polymer from the heat source. This is certainly not true for PVC. The difference is that PS and PMMA are not char-forming polymers, rather they degrade by a scission process that leads to the formation of either exclusively monomer (in the case of PMMA) or a mixture of monomer and oligomers (in the case of PS) ${ }^{[22]}$. For a char-forming polymer, the char that is formed will serve as a much more effective insulator than does the inorganic oxides that result from the clay and one has enhanced, and longer term, thermal stability.

The influence of DOP is shown in Fig. 6 . If one compares PVC-0-0 with PVC-0-35, oxygen accumulates much more rapidly in the presence of DOP than in its absence and this is also true even when the system contains $2 \%$ clay 
with the DOP. It is most likely that DOP is rising to the surface and its presence at the surface accounts for the increase in oxygen.

Fig. 7 provides the variation of the concentration of virgin PVC as a function of temperature while Fig. 8 shows the same information for PVC-30-0. The composition of virgin PVC at room temperature is 57 at.\% carbon, 33 at.\% chlorine and 10 at.\% oxygen. This relatively large amount of oxygen must arise from adventitious oxygen that is coated on the surface of the polymer. This gives a 1.7:1 ratio of carbon:chlorine rather than the 2:1 expected for PVC. Since one is examining the surface by this technique, this variation is not unexpected. The loss of chlorine begins at about $100^{\circ} \mathrm{C}$ and continues to $460^{\circ} \mathrm{C}$ when only $2 \%$ chlorine remains.

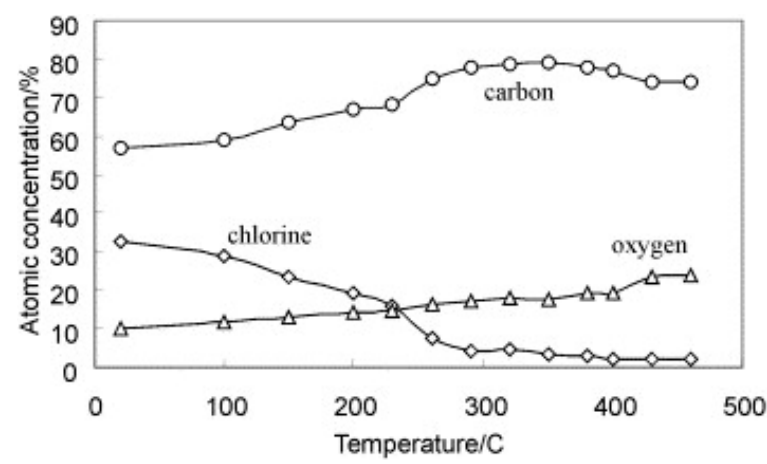

Fig 7. Atomic concentration of all elements for PVC-0-0 as a function of temperature.

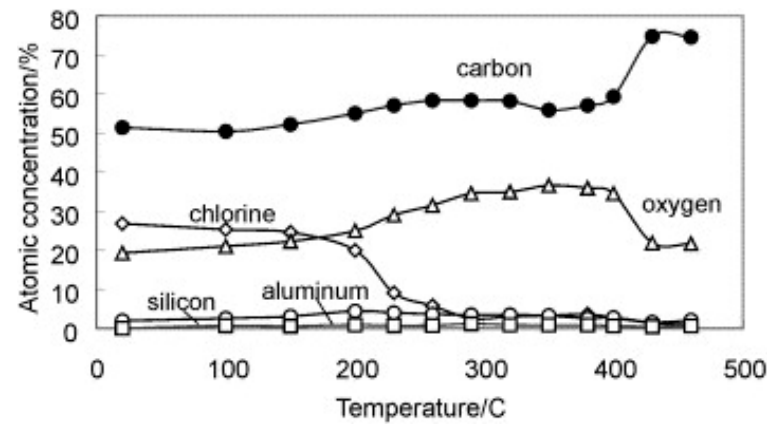

Fig. 8. Atomic concentrations of all elements for PVC-30-0 as a function of temperature.

Fig. 8 shows the at.\% composition for PVC-30-0 as a function of temperature. At ambient temperature the composition is 51.4 at.\% carbon, 27 at.\% chlorine, 19 at.\% oxygen and 2.6 at.\% silicon, the signal from aluminium is too weak to be observed. The $19 \%$ oxygen value includes both a contribution from the clay and adventitious oxygen contamination. The $\mathrm{C}: \mathrm{Cl}$ ratio is a little higher than in virgin PVC at 1.9:1; this difference is not significant. The loss of chlorine begins at somewhat higher temperature, $150^{\circ} \mathrm{C}$, than is observed for virgin PVC but the same amount remains at $460^{\circ} \mathrm{C}$ as in virgin PVC. This means that the degradation commences at higher temperature, the clay inhibits the loss of chlorine, but chlorine is still lost.

The surface of PVC and the PVC nanocomposite always dominated by carbon, and one does not observe the accumulation of oxygen, as seen for both PS and PMMA nanocomposites. This is no doubt due to the charforming tendency of PVC versus the complete volatilization of both PS and PMMA.

It is possible to differentiate between ionic and covalent chlorine based upon the binding energy of $\mathrm{Cl} 2 \mathrm{p}$. Above $250{ }^{\circ} \mathrm{C}$ for virgin PVC the $\mathrm{Cl} 2 \mathrm{p}$ peak splits into two components, one at $200.0 \pm 0.2 \mathrm{eV}$, assigned to covalent chlorine, and one peak at $198.0 \pm 0.2 \mathrm{eV}$, attributable to ionic chlorine; this is shown in $\underline{\text { Fig. } 9} \underline{[23]}$. 


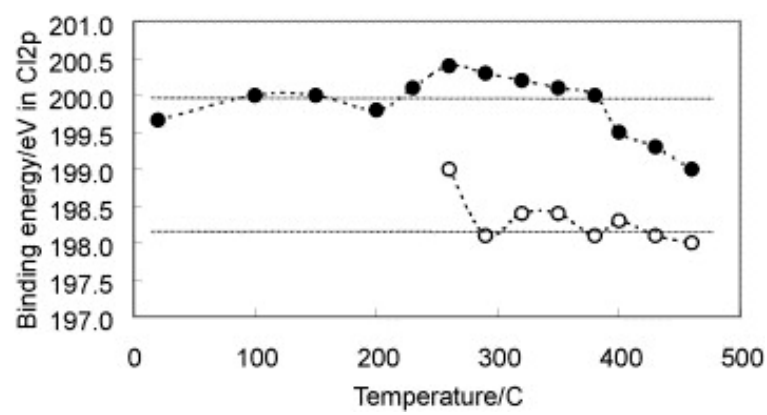

Fig. 9. Variation of binding energy in $\mathrm{Cl} 2 \mathrm{p}$ spectra for PVC-0-0 as function of temperature.

The variation of the covalent component for the nanocomposites is shown in Fig. 10 while the ionic component is shown in Fig. 11. It is interesting to note that all the chlorine is covalent up to about $200{ }^{\circ} \mathrm{C}$ when the covalent component begins to decrease and the ionic increases. This change occurs for both virgin PVC and the nanocomposites, but more covalent chlorine is converted to ionic in the presence of clay than in its absence and the amount of clay, whether 2 or $30 \%$, has no effect on the course of the reaction.

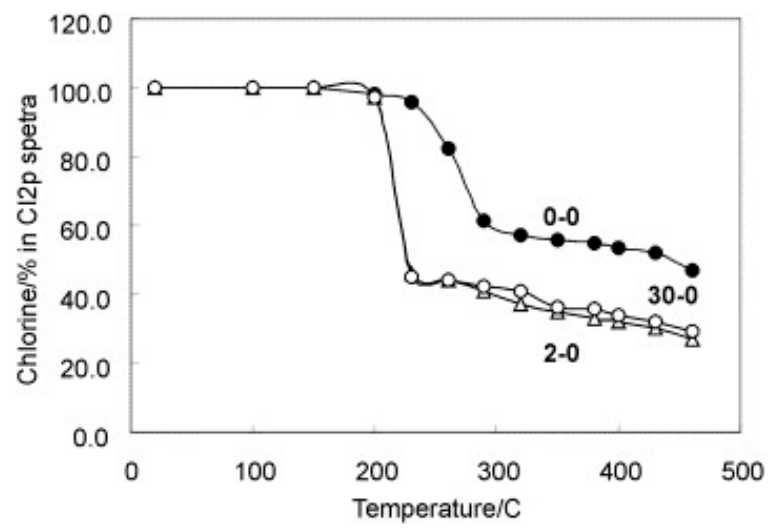

Fig. 10. Quantitative analysis of covalent chlorine as a function of temperature for PVC-clay nanocomposites without DOP.

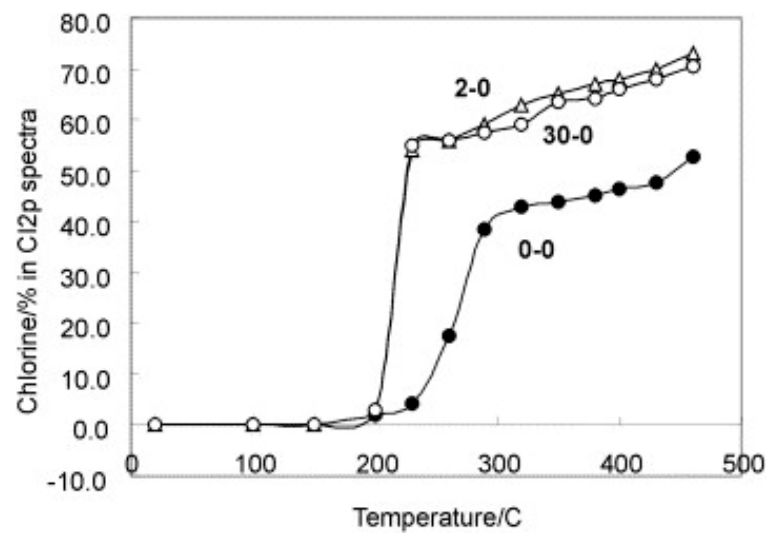

Fig. 11. Quantitative analysis of ionic chlorine as a function of temperature for PVC nanocomposites without DOP.

For virgin PVC, the commonly accepted mode of degradation is the loss of $\mathrm{HCl}$ with the formation of conjugated double bonds, which eventually cyclize to give aromatic rings. It is very difficult to imagine ionic chlorine from this system that would be on the surface of the degrading polymer. However, the initial loss of $\mathrm{HCl}$ will generate an allylic chlorine, which may be viewed as more ionic than a simple $\mathrm{C}-\mathrm{Cl}$ bond. Thus this variation in binding energy may be attributable to the $\mathrm{HCl}$ loss and the consequent formation of a more ionic-like moiety. The 
presence of the clay enhances the formation of this species, which means that $\mathrm{HCl}$ loss is slowed and the PVC degrades more slowly, in agreement with the previous observations from this XPS work.

The effect of DOP on the amount of ionic and covalent chlorine is shown in Fig. 12, Fig. 13, respectively. The presence of $35 \%$ DOP causes covalent chlorine to be retained to a much longer time at the temperature, thus the PVC component of this mixture is more stable. In some ways this is the same information that is shown in Fig. 2, where the variation of total chlorine is shown as a function of temperature. There are two steps for the degradation of PVC: the initial loss of $\mathrm{HCl}$ to form an allylic species and the degradation of this allylic species. In the first step, only covalent chlorine is lost while in the second, both ionic (allylic) and covalent chlorine are lost. If either of these two steps can be delayed, the thermal stability of PVC will be improved. Obviously, in the presence of DOP, the first step is postponed and the thermal stability of PVC is enhanced. In the presence of clay, covalent chlorine is more easily lost and the allylic chlorine concentration is higher in the clay-containing system than in virgin PVC, and thus the presence of the clay enhances the thermal stability by delayed loss of the allylic species.

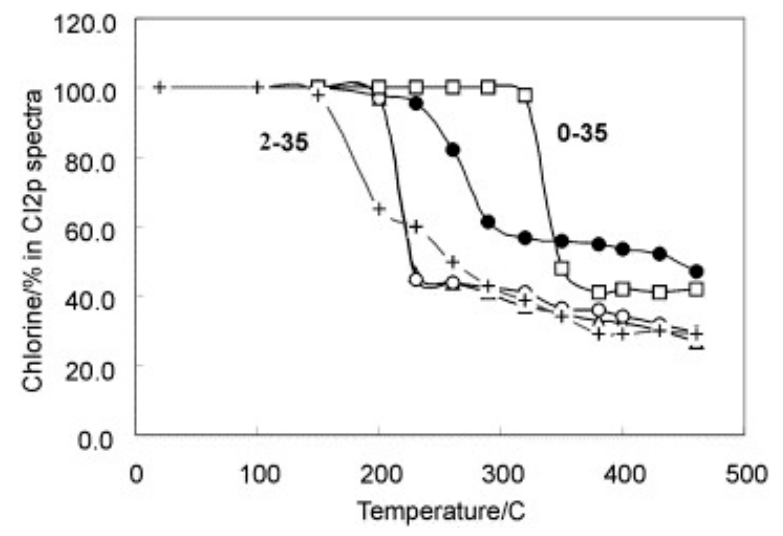

Fig. 12. Quantitative analysis of covalent chlorine as a function of temperature in $\mathrm{Cl} 2 \mathrm{p}$ spectra for PVC and its nanocomposites.

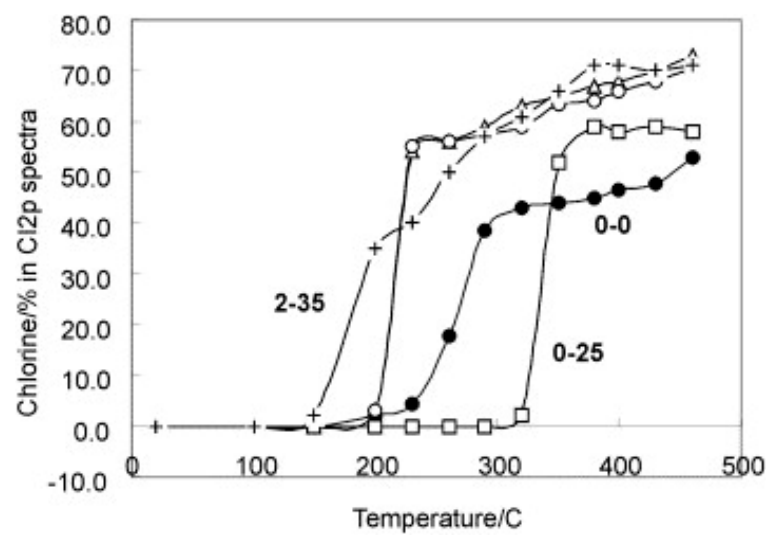

Fig. 13. Quantitative analysis of ionic chlorine as a function of temperature for PVC and its nanocomposites in $\mathrm{Cl} 2 \mathrm{p}$ spectra for PVC-clay-DOP.

\section{Conclusions}

The XPS of PVC nanocomposites is dramatically different than that of PS and PMMA. For polystyreneclay $\stackrel{[15]}{ }$ and poly(methyl methacrylate)-clay $\stackrel{[16]}{ }$ nanocomposites, the polymer is lost and the clay accumulates at the surface but for PVC the polymer forms a carbonaceous char which dominates at the surface. The presence of the clay stabilizes the allylic species, which are formed during the degradation and leads to an enhanced stability for PVC relative to that in the absence of the clay. 


\section{Acknowledgments}

Southern Clay Products graciously provided the clays used in this study.

\section{References}

[1] M. Alexandre, P. Dubois. Mater. Sci. Eng., 28 (2000), pp. 1-63

[2] E.P. Giannelis, R. Krishnamoorti, E. Manias. Adv. Polym. Sci., 138 (1999), pp. 107-147

[3] S. Qutubuddin, X. Fu. Nono-Surface Chemistry (2002), pp. 653-675

[4] D.J. Suh, O.O. Park. J. App.I Polym. Sci., 10 (2002), pp. 2143-2147

[5] C. Zeng, L.J. Lee. Macromolecules, 34 (2001), pp. 4098-4103

[6] J. Ma, Z. Qi, Y. Hu. J. App.I Polym. Sci., 82 (2001), pp. 3611-3617

[7] S.T. Lim, Y.H. Hyun, H.J. Choi. Chem. Mater., 14 (2002), pp. 1839-1844

[8] J. Zhu, A.B. Morgan, F.J. Lamelas, C.A. Wilkie. Chem. Mater., 10 (2001), pp. 3774-3780

[9] J. Zhu, P. Start, K.A. Mauritz, C.A. Wilkie. J. Polym. Sci.: Part A: Polym. Chem., 40 (2002), pp. 1498-1503

[10] J. Zhu, F.M. Uhl, A.B. Morgan, C.A. Wilkie. Chem. Mater., 12 (2001), pp. 4649-4654

[11] H. Ishida, S. Campbell, J. Blackwell. Chem. Mater., 12 (2000), pp. 1261-1267

[12] D. Wang, D. Parlow, Q. Yao, C.A. Wilkie. J. Vinyl Add. Tech., 7 (2001), pp. 203-213

[13] D. Wang, D. Parlow, Q. Yao, C.A. Wilkie. J. Vinyl Add. Tech., 8 (2002), pp. 139-150

[14] Wang D, Wilkie CA. J Vinyl Add Tech [in press].

[15] J. Wang, J. Du, J. Zhu, C.A. Wilkie. Polym. Degrad. Stab., 77 (2002), pp. 249-252

[16] Du J, Zhu J, Wilkie CA, Wang J. Polym Degrad Stab [in press].

[17] J.W. Gilman. Appl. Clay Sci, 15 (1999), pp. 31-49

[18] C.F. Cullis, M.M. Hirschler The combustion of organic polymers. Clarendon Press, Oxford (1981)

[19] J. Hao, S. Wu, C.A. Wilkie, J. Wang. Polym. Degrad. Stab, 66 (1999), pp. 81-86

[20] J. Hao, C.A. Wilkie, J. Wang. Polym. Degrad. Stab, 71 (2001), pp. 305-315

[21] H. Tu, J. Wang. Polym. Degrad. Stab, 54 (1996), pp. 195-203

[22] C.F. Cullis, M.M. Hirschler The combustion of organic polymers. Oxford University Press, Oxford (1981)

[23] Wang J, Wu W, Feng D. In: Wang J, editor. Introduction to electric spectroscopy (XPS/XAES/UPS). Beijing, China: Guofang Industrial Publishing House; 1992 [in Chinese]. 